\title{
INVOLUNTARY MIGRATION IMPACTS ON THE LOCAL COMMUNITY IN UNDERDEVELOPED AND DEVELOPING COUNTRIES: A REVIEW
}

\author{
Nur Aulia Rosni ${ }^{*} \&$ Rosilawati Zainol ${ }^{* *}$ \\ *First author, ${ }^{* *}$ Corresponding author \\ ${ }^{1,2}$ Centre for Sustainable Urban Planning and Real Estate (SUPRE), Faculty of Built \\ Environment, Universiti Malaya, Kuala Lumpur, Malaysia \\ ${ }^{2}$ Centre for Civilisational Dialogue, Universiti Malaya, Kuala Lumpur, Malaysia \\ (nurauliarosni@um.edu.my; rosilawatizai@um.edu.my) \\ Doi: https://doi.org/10.22452/jati.vol25no2.2
}

\begin{abstract}
Involuntary migration is the coerced movement of people to a place away from their home of origin. Refugees are protected under international law, and they cross international borders to escape the risk of serious harm in their origin countries (UNHCR, 2019). At the end of 2018, approximately 25 million refugees had crossed international borders. However, there is another type of migrants that is not well defined nor protected by international law, which is the undocumented migrants. UNHCR has reported that refugees and undocumented migrants tend to flee to the nearest neighbouring countries, which are usually low and middle-income countries, rather than first world countries. This paper attempts to examine the effects of involuntary migration on the locals by investigating the widespread impacts that have occurred globally and reflect the situation to South-East Asian countries. A systematic review approach based on the PRISMA Statement was applied in this study. The Web of Science and Scopus scientific databases have identified 34 related studies on the effects of involuntary migrations. Six (6) categories of impacts have been identified, which include i) employment impact, ii) physical and environmental impact, iii) economic impact, iv) social and demographic impacts, v) facilities, welfare and educational impact and lastly vi) safety and security impacts. Reviewing the implications of involuntary migration can be a significant step forward for policymakers to improve their understanding of the issues, opportunity, and challenges faced by host countries in managing its people and resources. Underdeveloped and developing countries in the South-East Asian Region, including Malaysia, can plan to respond and address refugee influx in effective and efficient ways through proper resource planning and regulating legal and administrative framework.
\end{abstract}

Keywords: involuntary migration, refugee, undocumented migrants, migration impacts, host country, systematic literature review, SLR 


\section{Introduction and Background}

Every year, the UNHCR reports that thousands of people involuntarily flee their countries in a desperate attempt to find safety because their lives are threatened by civil conflict (Maystadt \& Verwimp, 2014). The issue is not a recent phenomenon, and involuntary migration has been one of the most discussed global issues since the late 1970s. According to the UNHCR, refugees are people who flee their country by crossing the international border to find safety in another country. Refugees are identified and registered with the UNHCR, thus giving them some extent of human rights because they are protected by international law. The most common reasons that refugees are unwilling or unable to return to their origin country are because of a well-founded fear of being persecuted on grounds of religion, race, nationality, or political opinion. Statistical reports by UNHCR indicate that by the end of the year 2018, approximately 25 million of the world's population from various countries facing turmoil had crossed international borders. These 25 million people are registered with UNHCR and are thereby protected by international law. However, another category of migrants are not registered with UNHCR, which is known as undocumented migrants. Undocumented migrants may have involuntarily fled their countries due to well-founded reasons or due to other reasons such as environmental disaster, climate change, or critical economic deprivation in their home countries, or being socially outcast by the ruling government, or where they do not belong to any nationality. Undocumented migrants consist of illegal migrants, displaced persons, and stateless persons. Therefore, it is anticipated that the real number of involuntary migrants is more than the declared 25 million. In this paper, both refugees and undocumented migrants will be referred to as involuntary migrants.

Contrary to popular belief, the majority of these involuntary migrants do not arrive in industrialised first world countries but instead land into countries neighbouring their own due to the urgency to seek safety and reduce the risk of being injured or perishing during the transit. They are more likely to land in neighbouring countries that share almost similar socio-economic backgrounds. Low and middle-income countries host approximately $80 \%$ of refugees compared to $20 \%$ that settle in high-income first world countries (UNRIC, 2020). However, this significant portion of the involuntary migrant population only represents refugees who are registered with UNHCR, leaving out data on undocumented migrants (illegal workers, unregistered asylum seekers and stateless persons), which might be similar or even higher in number than the documented refugees. 
A study in 2016 showed that Asia Pacific countries received the most significant number of involuntary migrants as compared to countries in other regions. The flow of the involuntary migrants mainly spread to neighbouring countries adjacent to their home country (Lasimbang, Tong, \& Low, 2016). In 2010, Malaysia received nine million migrants from Indonesia, which covers half of a total of 18 million migrants. Lasimbang, Tong and Low (2016) mentioned in their research that the ratio of documented migrants to undocumented migrants in Malaysia in that year was 1:1. During World Refugee Day 2020, the UN Secretary-General mentioned that the burden of helping involuntary migrants is unevenly distributed, where the more impoverished countries hosted more migrants than the wealthier countries (UNRIC, 2020). As mentioned earlier, developing countries host four-fifths of the total percentage of involuntary migrants, and at the same time, anti-refugee sentiment is spreading wildly in industrialised first world countries (UNRIC, 2020).

Involuntary migrants have been exposed to extreme disadvantages. Due to their unequal status to the local community, involuntary migrants have faced insecurities in terms of employment rights, income, and limitations to access education and health care. Studies on undocumented migrants living in the European Union (EU) show that mental disorders and sustained injuries are common health concerns because they do not want to seek medical care out of the fear of being deported and because they lack awareness of their rights. In contrast, refugees receive better welfare in terms of health care because they are registered under UNHCR and are protected by international law. However, the level of health care received by refugees is fundamental and highly dependent on aid from other NGOs associated with UNHCR. As for undocumented migrants, they are being excluded not only in terms of health care, but also in the national statistics of their country of refuge, making development interventions targeting them difficult to execute. In addition, their illegal status restricts their access to legal advice and compensation for unjust treatment (Lasimbang et al., 2016). These extreme disadvantages faced by the involuntary migrants who are undocumented may cause them to resort to crime. This and the clash of different cultures will impact the local community and thus influence their acceptance towards the migrants. For instance, Germany was one of the developed countries in the EU that actively accepted involuntary migrants owing to the welcoming culture 'Willkommenskultur' of German citizens. Germany received a significant number of asylum seekers in 2015. However, since then the local public opinion has shifted, although not too severely. There is growing anti-refugee sentiment due to public anxiety and incidents of local people being attacked by involuntary migrants in 2016. Recently, German citizens have been concerned on the impact 
of large-scale involuntary migrations on their economy and society. However, a majority of German people are still willing to accept migrants on a temporary basis, and want these migrants to be sent back once the conditions in their home countries improve (Holloway, Smart, Foresti, \& Leach, 2019).

Typically, mass media and NGOs often pressure the international community to support the refugee population during a humanitarian crisis. However, not much information is known about the long-term impact of involuntary migration influx on local hosts, especially in underdeveloped and developing countries. A considerable amount of refugee-focused research has been conducted, but fewer studies have been carried out to understand the impact on local communities in the host countries, especially in terms of social, economic, political and environmental impacts. Hosting refugees may represent a drain on local resources, mainly since external aid is frequently insufficient. For example, the massive wave of refugee migrations from Syria in 2011 has caused severe economic and political repercussions in Turkey, which later proliferated to most countries in Europe (Ceritoglu, Yunculer, Torun, \& Tumen, 2017). Recently, the international community has realised the severe impact of largescale refugee migration on host country resources. There is increasing awareness on the undesirable effects of involuntary migration influx, which have been overlooked for too long. Receiving a high number of refugees at one time will strain the resources, services and infrastructure of host countries (Maystadt \& Verwimp, 2014). By exploring and comparing the experience of much-developed countries in EU and the United States of America (USA), as well as underdeveloped countries in Asia and Africa hosting involuntary migrants, the impacts of involuntary migration can be deeply understood. Underdeveloped and developing countries, especially in the South-East Asian region, can then prepare to countermeasure the negative impacts brought on by migrants and utilise the positive impacts for the benefit of their countries.

\section{Towards a systematic review framework}

A systematic review is the process of examining a formulated research question that uses orderly and precise means to identify and assess an appropriate number of studies critically. The method also aids the author in collecting and analysing data from recognised research, which can later be represented in statistical or non-statistical manners to summarise the results. By using a systematic review, the authors presented the specific research gap and justified the future direction of their research (Higgins et al., 2011; Shaffril, Krauss, \& Samsuddin, 2018). A systematic review of the literature on involuntary migration impacts on the local communities in host countries is critically lacking. This 
situation is proven through a preliminary systematic literature search using identified keywords related to the subject matter of this paper, where the result of the search indicates that 65 articles out of the total screened 99 articles had to be excluded because the content of the articles did not discuss the impact caused by involuntary migrations.

Therefore, this paper attempts to fill the gaps in identifying the effects refugees have posed on the local people. Peer review literature on this topic was used as a proxy of adaptation that provides a baseline of the involuntary migrant's impact on their host countries. The work fills an important gap in the literature, with most systematic review tending to investigate the adaptation and condition of the refugee community in host countries (Al-Husban \& Adams, 2016; Kovras \& Robins, 2016; van Kempen, Spiliotopoulou, Stojanovski, \& de Leeuw, 2017), or focused on their welfare and well-being (Karababa, 2019; Fauvelle-Aymar, 2014; Floyd \& Sakellariou, 2017; Greene et al., 2019). This study is vital because issues relating to conflicts faced by refugees is a global issue that vigorously poses a threat to resource management and distribution of host countries. Up to the present time, studies that provide a holistic baseline on the status of the impact of refugee migration on the local people are lacking (AlixGarcia, Walker, Bartlett, Onder, \& Sanghi, 2018). In recent years, a few researchers have called for the study of the impact of refugees in their host countries in order to formulate with a better solution for both parties and to produce a win-win situation (Asali, 2017; Bratsberg, Raaum, Røed, \& Schøne, 2014; Giuntella, 2012; Maystadt \& Verwimp, 2014; Tatah, Delbiso, RodriguezLlanes, Cuesta, \& Guha-Sapir, 2016; Wu et al., 2020).

A research question was formulated to guide the direction of this paper and assist the authors in constructing a relevant systematic review. The question seeks to find in what contexts do involuntary migrations impact social and economic development as well as the daily lives of the local community? Focus is given to involuntary migrants who have unwillingly fled their countries due to life-threatening situations and deprivations. Although this category of migrants is regarded as part of the involuntary migrant group by a few researchers, internally displaced persons and undocumented immigrants due to natural disaster and climate change are not included in this review. Even though the internally displaced person is forced to flee their home, they remain within their country's borders. They do not cross the international border, invalidating them from this research. On the other hand, undocumented migrants due to natural disaster would usually return to their place of origin once it has recovered and is safe. In addition, this paper has chosen not to include the impact of COVID-19 by 
refugees on the locals due to limited scholarly studies conducted in this region. It would be good if a future review could cover this impact.

\section{Research Methodology}

This section details the methodology adopted, which is the PRISMA Statement (Preferred Reporting Items Systematic Reviews and Meta-Analysis) approach. The reviewers have used PRISMA, which includes resources from scientific databases (Scopus and Web of Science). PRISMA is used to run the review by checking the eligibility and exclusion criteria of the articles, systematically reviewing materials that have been through the process of identification, screening, and eligibility. This process also includes data abstraction and analysis of the final articles included.

\section{Preferred Reporting Items for Systematic Reviews and Meta-Analyses (PRISMA)}

Preferred Reporting Items for Systematic reviews and Meta-Analyses or PRISMA is frequently applied within the built environment field. PRISMA poses three distinctive advantages in the articles reviewing process, which includes defining clear research questions that permit systematic research, identifying inclusion and exclusion criteria, and attempting to examine the extensive database of scientific literature within a specified time. The PRISMA Statement allows for a thorough search of terms related to refugee migration impacts towards the local community.

\section{Sources}

The review process relied on the two largest scientific databases, namely Scopus and Web of Science (WoS). Articles related to involuntary migration impacts were extracted from the Scopus database. It is one of the most extensive abstracts and citation databases of peer-reviewed literature. Scopus includes high-quality standards of journals with a range of diverse subject areas. WoS is a robust database providing journals with coverage of over 256 disciplines including subjects related to environmental studies, interdisciplinary social sciences, social issues and development and planning. It includes over a century of comprehensive backfile and citation data established by Clarivate Analytics and ranks them by three separate measures, namely citations, papers, and citations per paper. 


\section{Eligibility and Exclusion Criteria}

Eligibility and exclusion criteria are determined through types of literature. Journal articles with empirical data are selected, excluding review articles, book series, books, chapters in books and conference proceedings. The selected items were limited to those published between 2011 to 2020 (10 years) to keep the information recent and relevant. The search efforts excluded non-English publications and focused only on articles published in English to avoid difficulty in translating the articles. All the selected journal articles have been published, therefore excluding those that are still under the review stages. As the review process of the present paper focused on the impact of involuntary migration on the local community, the authors gave priority to articles indexed in the social science-based database and excluded articles published in a pure and clinical science index.

Table 1: Inclusion and Exclusion Criteria

\begin{tabular}{|l|l|l|}
\hline Criteria & Inclusion & Exclusion \\
\hline Timeline & $2011-2020$ & 2010 and before \\
\hline Document type & Article & $\begin{array}{l}\text { Review paper, book, chapter } \\
\text { in the book, conference paper }\end{array}$ \\
\hline Source type & Journal & Book, Book Series \\
\hline Publication stage & Final & Non-English \\
\hline Language & English & \\
\hline
\end{tabular}

\section{Systematic Review Process}

The systematic review process was conducted in four different phases. The review process started in December 2019 by identifying keywords used in the search process by relying on previous related studies and thesaurus. Several keywords have been identified to search relevant journals for the research.

Table 2: Identification of Keywords

\begin{tabular}{|l|l|}
\hline Database & Search String/Query String \\
\hline Scopus & $\begin{array}{l}\text { TITLE-ABS-KEY ( ("refugee" OR "immigrant" OR } \\
\text { "migrant" OR "displaced" OR "involuntary migration" OR } \\
\text { "force displacement") W/ ("impact" OR "effect" OR } \\
\text { "consequence" OR "concern" ) AND ("on local" OR "on } \\
\text { native" OR "on citizen" OR "on national") ) }\end{array}$ \\
\hline WoS & TS = (involuntary migration impact AND on Local) \\
\hline
\end{tabular}


The careful screening removed duplicated and unrelated articles. At this stage, from 330 articles eligible to be reviewed, a total of 231 articles were removed. The next stage is eligibility, where the full articles were assessed. After careful examination, a total of 65 articles were excluded as they did not focus on the impact caused by refugees on the local communities, were not empiricalbased articles, or did not focus on this topic from the social science perspectives. The last stage of the review resulted in a total of 34 articles that were later used for the content analysis.

\section{Data Abstraction and Analysis}

The selected articles were reviewed and analysed. Efforts were concentrated on specific studies that responded to the formulated research questions. The abstracts were first examined before the full articles were analysed in-depth to identify appropriate themes and sub-themes. Qualitative analysis was performed using the content analysis technique to identify subjects related to refugee impacts on the local community. The impacts were categorised based on the built environment and socio-demographic factors.

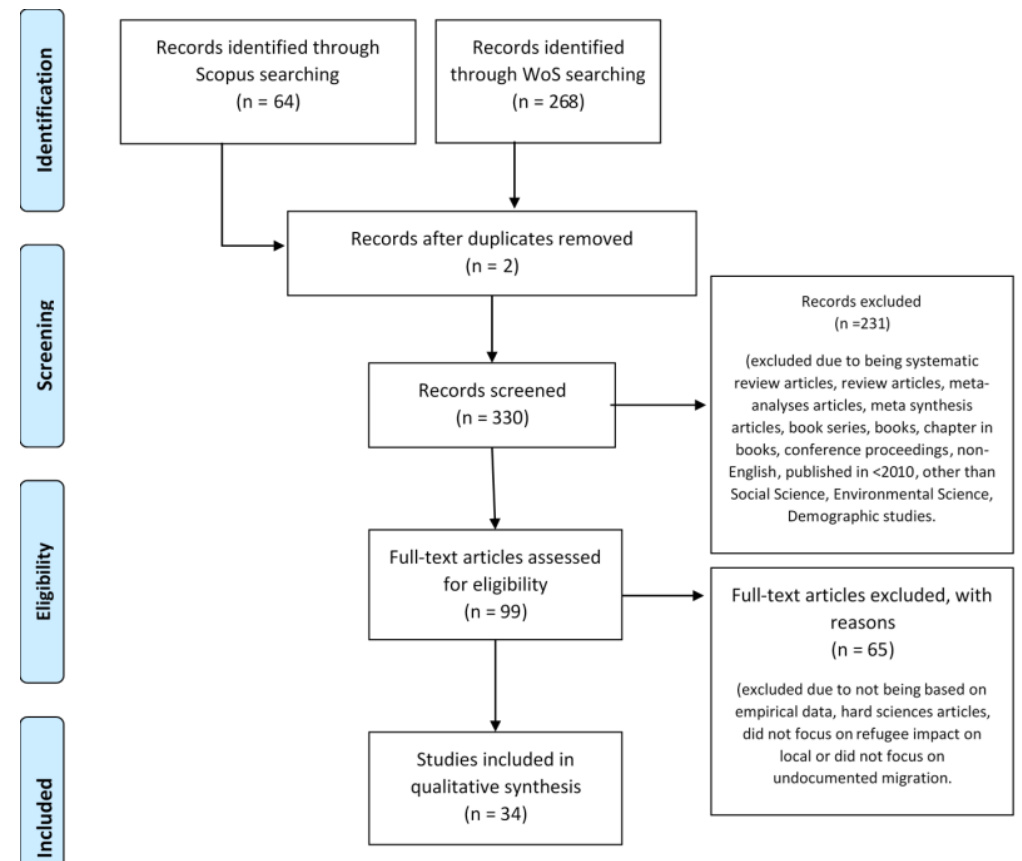

Figure 1: Systematic Review Process

(Source: PRISMA) 


\section{Findings and Discussion}

Examining the impact of involuntary migrations influx, either documented or undocumented, is critical for developing and underdeveloped countries compared to developed nations. This action is crucial due to the fact that $85 \%$ of involuntary migrants arrived in developing and underdeveloped countries that have limited resources to support the new arrivals compared to developed first world nations (Alix-Garcia et al., 2018; UNRIC, 2020). The arrival of involuntary migrants has contributed extra pressure on resource planning and management in terms of social, economic, environmental and, at a time, political difficulties faced by the host countries (Alix-Garcia et al., 2018; Fromentin, Damette, \& Zou, 2017). These impacts are substantial in underdeveloped countries with smaller population scales, making the number of refugees equal to, or in some places, outnumbering the local populace.

The review process has helped the researchers to collate the impacts of involuntary migration into a few categories. The results demonstrate the adequacy of the SLR method to assess the impact of involuntary migration towards the local host countries. The country's economy, levels of employment, and labour market are the most intensely debated topics in the majority of the extracted academic articles. Many researchers have agreed that the direct impact of involuntary migration is on employment rates, either positive or negative (Almosova, 2014; Ceritoglu et al., 2017; Giuntella, 2012; Kamaruddin \& Abdullah, 2018; Martins, Piracha, \& Varejão, 2018; Sun, 2013). The popular perception of the local community and some policymakers is that involuntary migrants "steal" jobs from the local people (Almosova, 2014; Asali, 2017; Ceritoglu et al., 2017; Giuntella, 2012; Martins et al., 2018; Maystadt \& Verwimp, 2014). Some researchers identify the impact of involuntary migrations on the host countries' physical development and natural environment (Ahmed, 2016; Karababa, 2019; Getahun, Poesen, \& Van Rompaey, 2017; Katsanevakis, 2015; Maystadt \& Verwimp, 2014; Spröhnle, Kranz, Schoepfer, Moeller, \& Voigt, 2016); economy (Maystadt \& Verwimp, 2014; Taylora et al., 2016; Vasilakis, 2018); sociodemographic (Al-Husban \& Adams, 2016; Fauvelle-Aymar, 2014; Vasilakis, 2018); facilities, welfare and education (Ahmed, 2016; Albornoz, Cabrales, \& Hauk, 2018; Bilgili, Loschmann, Fransen, \& Siegel, 2019; Jensen \& Rasmussen, 2011; Tan, Spiegel, Haskew, \& Greenough, 2016; Tatah et al., 2016); where the least studied impact is on the safety and security of the local community (Erensu \& Kaşli, 2016).

The findings of this study elaborate on six components that are affecting the local community. These components include employment, physical and 
environmental impacts, economic impacts, social and demographic impacts, facilities, welfare and education, and finally, safety and security impacts.

\section{Employment}

The impact of migration on a receiving country's economy, particularly its labour market, is an intensely debated topic. Although there is no official consensus in existing literature about the overall effect on local employment rate, there is still plenty of empirical evidence that suggests that involuntary migration has posed some effects (good and bad) on the employment opportunity of local people (Martins et al., 2018). According to Giuntella (2012), economic impact on the local labour market is one of the major concerns in several receiving nations, thus the most investigated topic by researchers. Many researchers believed that involuntary migration incursion of the host countries affects the employment opportunity of local people (Ceritoglu et al., 2017; Martins et al., 2018; Sun, 2013; UNRIC, 2020). The influx of involuntary migrants in large numbers has increased the local public's anxiety and fear that they need to compete with migrants for job opportunities. In European countries, almost half of the population are worried that the influx of refugees would cost them their jobs, and that the next generation of their people would need to compete with refugees in the labour market (Almosova, 2014). Several factors may have contributed to this sentiment; one of the most significant is that migrants are willing to work extra hours at bare minimum wages compared to the local people (Kamaruddin \& Abdullah, 2018). Most of the local people who had lost their jobs to involuntary migrants remained unemployed and faced a decline in job-seeking rates. Moreover, the local people who belong to vulnerable social classes such as young adult workers, the less-educated, women, and disabled people are more profoundly affected by the disadvantages of finding jobs as compared to the involuntary migrant worker.

In many industrialised countries, involuntary migrants, especially the refugees, are not permitted to work, nor are they provided with formal work permits. However, there are no specific measures to detect or control the migrants if they work illegally, and this situation will affect the labour market of the respective countries (Ceritoglu et al., 2017; Sun, 2013). As mentioned earlier, a few researchers had recorded that involuntary migrants are willing to work odd hours with smaller wages compared to local labour (Giuntella, 2012; Kamaruddin \& Abdullah, 2018). There appears to be a positive association between involuntary migrants and jobs that have been perceived as unattractive by local people based on the 3Ds perception (dark, dirty and dangerous job) 
(Kamaruddin \& Abdullah, 2018). Employers are also more prone to hire refugees since they provide inexpensive unskilled labour (Ceritoglu et al., 2017).

However, there also appears to be a positive association between the impact of involuntary migrants on the labour market. Several studies have examined the impact of involuntary migrations and employment opportunity that turned to have positive outcomes towards the country's economic growth. Hirschman (2014) and Hipp and Boessen (2012) proved that migration might increase the supply of workforce and employment competition but, at the same time, increase the nation's income. According to Alix-Garcia et al. (2018), the positive effect of refugees on the local economy seems to come through the availability of employment opportunities and price changes in agricultural and livestock markets that encourage new production. However, Asali (2017) argues that the impact of involuntary migration affects local groups differently based on factors such as skilled and unskilled labour. In addition, whether the outcome turns out to be positive or negative, the effect of mass migrations inflows is highly dependent on the background of the host countries and the occupation of the local inhabitants (Maystadt \& Verwimp, 2014). In rural areas, the influx of migrants may help to boost a local economy that depends on agriculture and livestock due to an increased demand from migrants. However, in the many cities where the economy depends on industry and construction, locals would need to compete for employment opportunities (Holloway et al., 2019).

\section{Physical and Environmental Impacts}

${ }_{2}$ Several investigators have reported a close correlation between involuntary migrations and negative impacts on the natural and physical environment. (Ahmed, 2016; Karababa, 2019; Getahun et al., 2017; Katsanevakis, 2015; Maystadt \& Verwimp, 2014; Spröhnle et al., 2016). The distance between local settlement areas and refugee camps has different physical and environmental impacts. Maystadt and Verwimp (2014) reported that a settlement area located in close proximity to a refugee camp faced problems such as unexpected degradation, noisy surrounding environment, spreading of diseases, compromised security and also cleanliness issues. Most of the refugee camps were erected at isolated locations that lacked infrastructure. Insufficient basic need services such as water supply, sanitation, hygiene and waste management increased pressure on the environment. Ahmed, (2016) identified several environmental issues in refugee camps, which include pollution to groundwater and soil due to the poor management of wastewater disposal. The polluted groundwater, which is also the water supply, caused many health issues to the refugees, as well as to the local communities that lived nearby the camps. 
Moreover, the environmental degradation caused by involuntary migrants does not only occur during their stay in the host country, but merely begins when refugees land on the shores of the host country. Katsanevakis, (2015) stated that the increasing arrival of refugees in Europe had led to a surge in the problem of marine litter, especially in the Aegean Sea, which is also the main entry point of refugees into Europe. Refugees discarded a massive amount of plastic, where almost $97 \%$ of plastic waste collected from the area were items that the refugees had used during their transit, such as inflatable boats, life jackets, clothes and other non-biodegradable waste. The high amount of plastic pollutants endangered the marine life in the coastal area and threatened the local economy that depended on the tourism value of these beaches.

The high number of refugee migration also posed a negative impact on the spatial arrangement of urban areas. Resettlement programs for refugees increased pressure on forest resources and vegetation area. Farmers are prone to enhance and expand agricultural activities to satisfy the needs/demands from refugees. From analysis of forest cover change, researchers have found that many countries that host refugees have lost approximately $80 \%$ of forest area since the 1950s due to settlement and agriculture activities (Getahun et al., 2017; Spröhnle et al., 2016). The influx of refugees has also led to spatial transformation in urban areas. In cities where refugees settled, national and international NGOs start working and living in these cities, which has influenced the demand and supply of housing facilities, which subsequently led to economic-migration development. This type of development is always associated with a lack of organisation in the city and caused gentrification of the urban area by encouraging more informal sectors to flourish in the city.

Another problem that arises from spatial transformation is the prevailing tendency in the organisation of the city and the planning of social services focusing on refugees, seeing them as newcomers. This approach neglects their existence in the city as agents who share responsibility with the rest of the dwellers. In addition to this, locals are likely to move away from an area that has a higher population of involuntary migrants and resettle in new areas. The resettlement of the population where new land areas are opened to accommodate this will result in the problem of deforestation (Karababa, 2019).

\section{Economic Impacts}

The increasing number of involuntary migrants globally has gained the interest of many researchers. However, there is still uncertainty whether involuntary migrants bring a negative or positive impact on the local economy. The issues raised have been controversial and little understood by many (Taylora et al., 
2016). In the United States, there is widespread belief that refugee immigration is harmful to the economy and well-being of the local people (Hirschman, 2014). As previously discussed, refugees and undocumented migrants tend to be more willing to work at lower wages, which threatens the employment opportunity of the local population (Giuntella, 2012; Kamaruddin \& Abdullah, 2018). In some host countries, refugees are not allowed to work, and only depend on welfare provided by the receiving host countries, the UN and other NGOs. In this case, refugees receive public benefits, such as healthcare, education and welfare, without paying their fair share of taxes. However, there is little evidence that supports these claims (Hirschman, 2014).

Some studies suggest that refugee camps have mixed economic consequences on the local population, mainly in price increases, wage competition and competition for natural resources. Wealthier host countries are most likely to benefit from the presence of involuntary migrants. Poorer host countries, however, will have to compete for the lack of natural resources, basic need and services (Maystadt \& Verwimp, 2014). Taylora et al. (2016) revealed that when refugees were allowed to interact with the economic activities in their surrounding areas, they could generate positive income spill-overs for hostcountry households through cash aid spending. However, if refugees received aid in the form of food and daily needs, the economic benefits to the local people would be reduced. That is why the structure of the aid received by refugees is crucial in determining the local people's acceptance of their presence and increase the refugees' potential to create economic benefits for their host countries (Maystadt \& Verwimp, 2014; Taylora et al., 2016).

\section{Social and Demographic Impacts}

Social impact is the net effect of activities on a community that includes the wellbeing of individuals and families. Social impact is associated with changes in moral value and conduct, behaviour, family structure, connection, lifestyle, safety, creative expression, economic benefits, opportunities, employment, education, health, social well-being, risk to violence, community problems, and the environment (McCombes, Vanclay \& Evers, 2015; Butcher et al., 2015; Nzeadibe et al., 2015). Studying the aspects of social impact is important because the presence of involuntary migrants will affect the level of happiness of the local people. From the perspective of social factors, the arrival of involuntary migrants in an area will cause the rise of new ethnic groups in the host country. This has led to changes in the ethnic composition of host countries and increased ethnic tension between minority and majority members of the population. In countries with higher levels of taxation, the local people start questioning the aid given to 
refugees by their government and later influence the political voting process in their states. The refugee "issue" is often profoundly political as a high density of migrants in local areas impacts communities (Fauvelle-Aymar, 2014). The antiimmigration attitude among the locals for economic and emotional reasons is currently on the rise, especially in European countries that had initially accepted refugees with open arms (Fauvelle-Aymar, 2014; Ling, Mohd. Rosli, Marhalim, \& Mohamed Musthafa, 2017; Vasilakis, 2018).

\section{Facilities, Welfare, and Education}

Based on several types of research, there is a lack of effect on the local community in terms of educational quality because involuntary child migrants do not have access to formal education. However, in some countries, documented migrants or refugees were absorbed into the society as immigrants. Schools with a high number of immigrant students faced problems in terms of educational quality. Local children in schools with a higher percentage of immigrant students tend to score lower marks, especially in reading and math (Albornoz et al., 2018; Jensen \& Rasmussen, 2011). Hosting refugees may represent a drain on local resources, mainly since external aid is frequently insufficient. Refugee influx also affects the health services of the hosting community (Tatah et al., 2016). Numerous simultaneous complex humanitarian emergencies strain the ability of local governments and the international community to respond, underscoring the importance of cost-effective use of limited resources (Tan et al., 2016). In many underdeveloped and developing countries, hosting a massive number of involuntary migrants with little resources, such as technical and economic capacities, will create competition between the involuntary migrants and the local people in terms of their access to clean water supply, sanitation and hygiene (Ahmed, 2016).

\section{Safety and Security Impacts}

When involuntary migrants flee from their country, they carry safety and security threats to their host countries. From the moment they arrive in the host country, they expose these threats to the local community. This is due to the absence of the personal data of each involuntary migrant in the host country, thus making it difficult and almost impossible for the host government to identify involuntary migrants with criminal records. The presence of immigrant communities discourages locals from staying in that area. It has been reported that criminal cases linked with undocumented migrants and refugees usually include sexual assault, theft, robbery, public dispute, vandalism and many other criminal cases (Misman, Mohd Adnan, Firdaus, \& Ahmad, 2017). This matter has 
been made worse due to the aggressive behaviour of the immigrants who like to make noise, fight among themselves and become intoxicated and behave rudely towards the local people. Thus, the local community seemed to be uncomfortable to share facilities and live in the same area as migrant communities due to the high risk to their safety and security (Kudo, 2013; Ling et al., 2017). In the EU, refugees who try to cross borders are prone to acts of violence towards the locals, especially in highways and main roads connecting different countries due to their desperation to cross over (Erensu \& Kaşli, 2016). Another threat faced by the local community is in terms of health safety. Vast attention has been given on vulnerable involuntary migrant groups such as women and children due to their risk of being tricked into prostitution, and increased exposure to sexual abuse and exploitation. They have been exploited as sex workers serving the local community, thus exposing them to a high risk of contracting sexually transmitted diseases, such as HIV. Migration has been highlighted as one of the significant factors for the rapid transmission of HIV (Lasimbang et al., 2016).

\section{Conclusion and Recommendations}

This research attempts to recognise potential effects that may impact the local community's well-being, especially in terms of long-term social and economic development. It is crucial to understand the impacts of refugee inflows to the social and economic development of host countries and the method by which the local communities are affected by the presence of sizeable refugee populations. Based on the systematic review approach adopted in this paper, the authors have identified several key issues surrounding involuntary migrants and the local people of the host countries. The main issues revolve around the fact that even though much previous research has acknowledged that there are potential effects that may impact the long-term social and economic development of a refugeereceiving country, a more profound understanding of the aspect is somewhat limited. As a result, the growing number of involuntary migrants are presenting increased challenges for the migrants, hosts, and governments alike. In this paper, the authors have discovered that limited research has been conducted where the main focus of the research is the local host countries. Most of the existing research conducted by researchers from different countries have focused on involuntary migrants. The considerable gap in understanding the impact posed by involuntary migrants has caused public anxiety and anti-immigrant sentiments, especially in industrialised countries. Such a situation will increase the burden of developing and underdeveloped countries because the local community in industrialised countries no longer want to receive these migrants. UNHCR has reported that there is a huge imbalance in the distribution of 
involuntary migration, where $80 \%$ of receiving countries are developing and underdeveloped countries, whilst anti-migration outcries continue to increase in industrialised countries. The authors firmly believe this situation happens due to the poor understanding of the real impacts of involuntary migration on local people. In addition, a majority of the limited research with a main subject focus on the local community of host countries has focused on the impact in terms of employment issues, physical and environmental impacts, and economic impacts. Less attention has been given to other factors such as social impacts, facilities and welfare impacts, as well as safety and security impacts to the local people. These impacts have led to rising ethnic tension in many host countries, which in most cases has resulted in violent crime cases. By understanding and acknowledging the impact of forced migrations on both migrants and the host population, different countries can work together to reduce the imbalanced distribution of involuntary migrants and help to turn the action of receiving involuntary migrants from something that is significantly and typically associated with disadvantages into advantages for the host countries. Future studies in relation to this paper should focus on the impact of involuntary migration during the COVID-19 outbreak on both involuntary migrants and also the local communities of host countries.

\section{Acknowledgments}

Authors wish to thank the Universiti Malaya for the research grant (GPF001F2018) to enable this study to take place.

\section{References}

Ahmed, S. S. (2016). A Study of maintaining and improving the WASH services provided by local and international agencies in selected refugee camps in Kurdistan Region, Iraq. European Journal of Sustainable Development, 6(3), 6876. https://doi.org/10.14207/ejsd.2016.v5n3p68

Al-Husban, M., \& Adams, C. (2016). Sustainable refugee migration: A rethink towards a positive capability approach. Sustainability (Switzerland), 8(5), 110. https://doi.org/10.3390/su8050451

Albornoz, F., Cabrales, A., \& Hauk, E. (2018). Immigration and the school system. Economic Theory, 65(4), 855-890. https://doi.org/10.1007/s00199-0171041-4

Alix-Garcia, J., Walker, S., Bartlett, A., Onder, H., \& Sanghi, A. (2018). Do refugee camps help or hurt hosts? The case of Kakuma, Kenya. Journal of 
Development

Economics,

130,

$66-83$.

https://doi.org/10.1016/j.jdeveco.2017.09.005

Almosova, A. (2014). Labor market institutions and the effect of immigration on national employment. Business and Economic Horizons, 9(4), 53-74. https://doi.org/10.15208/beh.2013.22

Asali, M. (2017). The effects of (different types of) immigrants on labor market outcomes of (different groups of) natives. International Journal of Manpower, 38(3), 338-353. https://doi.org/10.1108/IJM-11-2014-0229

Bilgili, Ö., Loschmann, C., Fransen, S., \& Siegel, M. (2019). Is the education of local children influenced by living near a refugee camp? evidence from host communities in Rwanda. International Migration, 57(4), 291-309. https://doi.org/10.1111/imig.12541

Bratsberg, B., Raaum, O., Røed, M., \& Schøne, P. (2014). Immigration wage effects by origin. Scandinavian Journal of Economics, 116(2), 356-393. https://doi.org/10.1111/sjoe.12053

Butcher, F., Galanek, J. D., Kretschmar, J. M., \& Flannery, D. J. (2015). The impact of neighborhood disorganisation on neighborhood exposure to violence, trauma symptoms, and social relationship among at-risk youth. Social Sciences \& Medicine, 146, 300-306.

Ceritoglu, E., Yunculer, H. B. G., Torun, H., \& Tumen, S. (2017). The impact of Syrian refugees on natives' labor market outcomes in Turkey: Evidence from a quasi-experimental design. IZA Journal of Labor Policy, 6(1), 1-28. https://doi.org/10.1186/s40173-017-0082-4

Erensu, A., \& Kaşli, Z. (2016). A tale of two cities: Multiple practices of bordering and degrees of "transit" in and through Turkey. Journal of Refugee Studies, 29(4), 528-548. https://doi.org/10.1093/jrs/few037

Fauvelle-Aymar, C. (2014). The welfare state, migration, and voting rights. Public Choice, 159(1-2), 105-120. https://doi.org/10.1007/s11127-012-0024-z

Floyd, A., \& Sakellariou, D. (2017). Healthcare access for refugee women with limited literacy: Layers of disadvantage. International Journal for Equity in Health, 16(1), 1-10. https://doi.org/10.1186/s12939-017-0694-8

Fromentin, V., Damette, O., \& Zou, B. (2017). The global economic crisis and the effect of immigrant workers on native-born employment in Europe. World Economy, 40(6), 1068-1088. https://doi.org/10.1111/twec.12394

Getahun, K., Poesen, J., \& Van Rompaey, A. (2017). Impacts of resettlement programs on deforestation of moist evergreen Afromontane forests in Southwest Ethiopia. Mountain Research and Development, 37(4), 474-486. https://doi.org/10.1659/mrd-journal-d-15-00034.1

Giuntella, O. (2012). Do immigrants squeeze natives out of bad schedules? 
Evidence from Italy. IZA Journal of Migration, 1(1). https://doi.org/10.1186/2193-9039-1-7

Greene, M. C., Rees, S., Likindikoki, S., Bonz, A. G., Joscelyne, A., Kaysen, D., Nixon, R. D. V., Njau, T., Tankink, M. T. A., Tiwari, A., Ventevogel, P., Mbwambo, J. K. K., \& Tol, W. A. (2019). Developing an integrated intervention to address intimate partner violence and psychological distress in Congolese refugee women in Tanzania. Conflict and Health, 13(1), 1-16. https://doi.org/10.1186/s13031-019-0222-0

Higgins, J.P.T., Altman, D.G., Gøtzsche, P.C., Jüni, P., Moher, D., Oxman, A.D. (2011). The Cochrane Collaboration's tool for assessing risk of bias in randomised trials. BMJ (Online) 343 (7829):1-9. https://doi.org/10.1136/bmj.d5928.

Hirschman, C. (2014). Immigration to the United States: Recent trends and future prospects. Malaysian Journal of Economic Studies, 51(1), 69-85.

Hipp, J. R. \& Boessen, A. (2012). Consequences of immigration for Southern California neighbourhoods over fifty years. The American Academy of Political and Social Sciences, 641, 192-219.

Holloway, K., Smart, C., Foresti, M., \& Leach, A. (2019, November). Public narratives and attitudes towards refugees and other migrants: UK country profile. London: ODI. Retrieved from https://www.odi.org/sites/odi.org.uk/files/resource-documents/12969.pdf

Jensen, P., \& Rasmussen, A. W. (2011). The effect of immigrant concentration in schools on native and immigrant children's reading and math skills. Economics of Education Review, 30(6), 1503-1515. https://doi.org/10.1016/j.econedurev.2011.08.002

Kamaruddin, R., \& Abdullah, N. (2018). Determinants of job satisfaction among Malaysian youth working in the oil palm plantation sector. Journal of Agribusiness in Developing and Emerging Economies, 8(4), 678-692. https://doi.org/10.1108/JADEE-06-2017-0063

Karababa, P. (2019). Adding the "new" inhabitant to the design of urban area and social work for refugees. Journal of Economy Culture and Society, 60, 45-60. https://doi.org/10.26650/JECS2019-0045

Katsanevakis, S. (2015). Illegal immigration in the eastern Aegean Sea: A new source of marine litter. Mediterranean Marine Science, 16(3), 605-608.

Kovras, I., \& Robins, S. (2016). Death as the border: Managing missing migrants and unidentified bodies at the EU's Mediterranean frontier. Political Geography, 55, 40-49. https://doi.org/10.1016/j.polgeo.2016.05.003

Kudo, S. (2013). Securitisation of undocumented migrants and the politics of insecurity in Malaysia. Procedia Environmental Sciences 17, 947-956. 
Lasimbang, H. B., Tong, W. T., \& Low, W. Y. (2016). Migrant workers in Sabah, East Malaysia: The importance of legislation and policy to uphold equity on sexual and reproductive health and rights. Best Practice $\mathcal{E}$ Research Clinical $\begin{array}{llll}\text { Obstetrics } & \mathcal{E} & \text { Gynaecology, 32, 113-123. }\end{array}$ https://doi.org/10.1016/j.bpobgyn.2015.08.015

Ling, O. H. L., H., Mohd. Rosli, N. N, F., Marhalim, F. A., \& Mohamed Musthafa, S. N. A. (2017). Social impact of foreign immigrants in affordable housing area. Case study: Mentari Court, Selangor, Malaysia. Planning Malaysia: Journal of the Malaysian Institute of Planners, 15(2), 37-50.

Martins, P. S., Piracha, M., \& Varejão, J. (2018). Do immigrants displace native workers? Evidence from matched panel data. Economic Modelling, 72, 216222. https://doi.org/10.1016/j.econmod.2018.01.019

Maystadt, J. F., \& Verwimp, P. (2014). Winners and losers among a refugeehosting population. Economic Development and Cultural Change, 62(4), 769 809. https://doi.org/10.1086/676458

McCombes, L., Vanclay, F., \& Evers, Y. (2015). Putting social impact assessment to the test as a method for implementing responsible tourism practice. Environmental Impact Assessment Review, 55, 156-168.

Misman, N., Mohd Adnan, H., Firdaus, A. S., \& Ahmad, C. M. (2017). Foreign nationals as offenders and victims in Malaysian crime news. SHS Web of Conferences, 33. https://doi.org/10.1051/shsconf/20173300028

Nzeadibe, T. C., Ajaero, C. K., Okonkwo, E. E., Okpoko, P. U., Akukwe, T. I., \& Njoku-Tony, R. F. (2015). Integrating community perceptions and cultural diversity in social impact assessment in Nigeria. Environmental Impact Assessment Review, 55, 74-83.

Shaffril, H. A. M., Krauss, S. E., \& Samsuddin, S. F. (2018). A systematic review on Asian's farmers' adaptation practices towards climate change. Science of the Total Environment, 644, 683-695. https://doi.org/10.1016/j.scitotenv.2018.06.349

Spröhnle, K., Kranz, O., Schoepfer, E., Moeller, M., \& Voigt, S. (2016). Earth observation-based multi-scale impact assessment of internally displaced person (IDP) camps on wood resources in Zalingei, Darfur. Geocarto International, 31(5), 575-595. https://doi.org/10.1080/10106049.2015.1062053

Sun, R. (2013). Kinetics of jobs in multi-link cities with migration-driven aggregation process. Economic Modelling, 30(1), 36-41. https://doi.org/10.1016/j.econmod.2012.08.013

Tan, T. M., Spiegel, P., Haskew, C., \& Greenough, P. G. (2016). Does spending on refugees make a difference? A cross-sectional study of the association between refugee program spending and health outcomes in 70 sites in 17 
countries. Conflict and Health, 10(1), 1-11. https://doi.org/10.1186/s13031-0160095-4

Tatah, L., Delbiso, T. D., Rodriguez-Llanes, J. M., Cuesta, J. G., \& Guha-Sapir, D. (2016). Impact of refugees on local health systems: A difference-indifferences analysis in Cameroon. PLoS ONE, 11(12), 1-11. https://doi.org/10.1371/journal.pone.0168820

Taylora, J. E., Filipski, M. J., Alloush, M., Gupta, A., Valdes, R. I. R., \& GonzalezEstrada, E. (2016). Economic impact of refugees. Proceedings of the National Academy of Sciences of the United States of America, 113(27), 7449-7453. https://doi.org/10.1073/pnas.1604566113

UNRIC. (2020). New report: Developing countries host $80 \%$ of refugees. Europe, United Nations Regional Information Center for Western. Retrieved from https://www.unric.org/en/world-refugee-day/26978-new-reportdeveloping-countries-host-80-of-refugees-

van Kempen, E. A., Spiliotopoulou, E., Stojanovski, G., \& de Leeuw, S. (2017). Using life cycle sustainability assessment to trade off sourcing strategies for humanitarian relief items. International Journal of Life Cycle Assessment, 22(11), 1718-1730. https://doi.org/10.1007/s11367-016-1245-z

Vasilakis, C. (2018). Massive migration and elections: Evidence from the refugee crisis in Greece. International Migration, 56(3), 28-43. https://doi.org/10.1111/imig.12409

Wu, W.-p., Chen, Z.-g., \& Yang, D.-x. (2020). Do internal migrants crowd out employment opportunities for urban locals in China? - Reexamining under the skill stratification. Physica A: Statistical Mechanics and Its Applications, 537. https://doi.org/10.1016/j.physa.2019.122580

Date received: 9 May 2020 Date of acceptance: 15 December 2020 